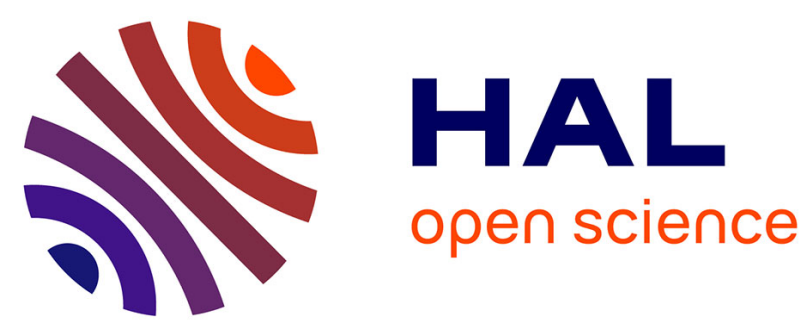

\title{
Experimental investigation of an actively controlled automotive cooling fan using steady air injection in the leakage gap
}

Tarik Azzam, Richard Paridaens, Florent Ravelet, Sofiane Khelladi, Hamid Oualli, Farid Bakir

\section{To cite this version:}

Tarik Azzam, Richard Paridaens, Florent Ravelet, Sofiane Khelladi, Hamid Oualli, et al.. Experimental investigation of an actively controlled automotive cooling fan using steady air injection in the leakage gap. Proceedings of the Institution of Mechanical Engineers, Part A: Journal of Power and Energy, 2017, 231, pp.59. 10.1177/0957650916688120 . hal-01361073

\section{HAL Id: hal-01361073 \\ https://hal.science/hal-01361073}

Submitted on 6 Sep 2016

HAL is a multi-disciplinary open access archive for the deposit and dissemination of scientific research documents, whether they are published or not. The documents may come from teaching and research institutions in France or abroad, or from public or private research centers.
L'archive ouverte pluridisciplinaire $\mathbf{H A L}$, est destinée au dépôt et à la diffusion de documents scientifiques de niveau recherche, publiés ou non, émanant des établissements d'enseignement et de recherche français ou étrangers, des laboratoires publics ou privés. 


\section{Experimental}

investigation of active

control by steady air

injection in the

leakage gap of an

axial shrouded

cooling fan
Journal Title

XX(X):2-13

(C)The Author(s) 0000

Reprints and permission:

sagepub.co.uk/journalsPermissions.nav

DOI: $10.1177 /$ ToBeAssigned

www.sagepub.com/

SAFE_Logo-eps-converted-to.pdf

\title{
Tarik Azzam ${ }^{1,2}$, Richard Paridaens ${ }^{1}$, Florent Ravelet ${ }^{1}$, Sofiane Khelladi $^{1}$, Hamid Oualli ${ }^{2}$, Farid Bakir ${ }^{1}$
}

\begin{abstract}
In an axial fan, a leakage flow driven by a pressure gradient between the pressure side an suction side occurs in the gap between the shroud and the casing. This leakage flow is in opposite direction to the main flow and is responsible for important energy dissipations. Therefore, many authors have worked to understand this phenomenon in order to reduce these inherent energy losses. Up till now, most of the studies reported in literature are passive solutions. In this paper, an experimental controlling strategy is suggested to reduce the leakage flow rate. To this aim, a fan with hollow blades and a specific drive system were designed and built for air injection. Air is injected in the tip clearance gap at the fan periphery. The experiment was performed for 3 rotation speeds, 5 injection rates and 2 configurations: 16 and 32 injection holes at the fan periphery. The experimental results of this investigation are presented in this article.
\end{abstract}

\section{Keywords}

Active control, leakage flow, air injection, axial fan, hollow blades. 


\section{Nomenclature}

$D \quad$ diameter radius (m)

Gain power gain added by the control

$P \quad$ power delived by the fan (W)

$P_{0} \quad$ power delived by the fan for $q_{\text {inj }}=0(\mathrm{~W})$

$q_{\text {inj }} \quad$ injection rate $\left(\mathrm{m}^{3} . \mathrm{s}^{-1}\right)$

$q_{\max }$ maximum fan flow rate $\left(\mathrm{m}^{3} \cdot \mathrm{s}^{-1}\right)$

$q_{v}$ fan flow rate $\left(\mathrm{m}^{3} \cdot \mathrm{s}^{-1}\right)$

$R_{e} \quad$ fan Reynolds number

$R_{\text {int }}$ hub radius (m)

$R_{\text {max }}$ tip radius (m)

$x_{\text {fan }}$ relative position between the fan and the carter (m)

$x_{\text {holes }}$ position of the injection holes on the casing (m)

$W \quad$ relative velocity of the fan $(\mathrm{m} / \mathrm{s})$

$\Delta P$ pressure difference generated by the fan $(\mathrm{Pa})$

$\mu \quad$ air dynamic viscosity (Pa.s)

$\phi \quad$ flow coefficient

$\psi \quad$ static pressure coefficient

$\rho \quad$ mass density $\left(\mathrm{kg} . \mathrm{m}^{-3}\right)$

\section{Introduction}

In recent years, more and more investigations on turbomachinery deal with the control by tip injection. In fact, this type control could improve different aspects of the device which could not be enhanced by the geometry refinement. By using injection upstream of the rotor, Weigl et al. (1) succeeded to stabilize rotating stall and surge in a transonic compressor which provided an enlargement of the operating range. Rhee et al. (2) increased the lift of a hydrofoil by injection control. Eberlinc et al. $(3 ; 4 ; 5)$ experimentally increased the pressure of an axial fan composed of hollow blades by a rate of $6 \%$. This gain was due to a free jet applied at the trailing edge of the blades. This

${ }^{1}$ DynFluid, Arts et Métiers, 151 boulevard de l'Hôpital, 75013 Paris, France

${ }^{2}$ Ecole Militaire Polytechnique, Laboratoire de Mécanique des Fluides, Algiers, Algeria

Corresponding author:

Richard Paridaens, Arts et Métiers, 151 boulevard de l'Hôpital, 75013 Paris, France

Email: richard.paridaens@ensam.eu

Prepared using sagej.cls 
free jet flow led to flow velocity increasing and adverse pressure gradient decreasing in the boundary layer. Wang and Zhao (6) experimentally and numerically investigated a transonic turbine cascade with different trailing edge ejection. As Eberlinc et al., the authors successfully reduced the vortex at the trailing edge of the blades.

This paper focuses on the injection used to reduce the phenomenon of leakage flow occurring at the blade tip. This flow driven by the pressure difference between the pressure side and suction side is responsible for important energy dissipations. This is certainly the reason why a huge number of authors are involved in such a problem investigation and sought mainly to enlight the underlying mechanisms behind this phenomenology. Neuhaus and Neise (7) attempted to reduce the leakage flow of an axial fan by applying active flow control in the tip region of the impeller. They injected air in the opposite direction of the flow by slit nozzles flush mounted in the inner casing wall. With this process, the authors succeeded to shift the stall point towards lower flow rates and to enlarge the using range of the fan characteristics by $62 \%$. They also increased the pressure of $28 \%$ and the efficiency by about $10 \%$. The investigation of Morris and Foss (8) was motivated by the relatively large $(2.5 \mathrm{~cm})$ tip clearance required in automotive cooling fans. They delivered by a fixed shroud a jet of high momentum air into the tip clearance gap region and succeeded to enhance the both the performance and the efficiency at higher flow rates. With the same aerodynamic fixed shroud concept, Neal and Foss (9) investigated the impact of air injection into smaller tip clearance than Morris and Foss. The authors increased the flowrate by $34 \%$ and the efficiency by $17 \%$ with the air injection system. Niu and Zhang (10) measured the effect an active tip-clearance control method based on tip injection in a high-turning axial turbine cascade. The authors injected through a row of 10 equidistant holes, directing towards the pressure surface at an angle of $45^{\circ}$ relative to the blade tip surface. They found that tip injection can effectively reduce tip clearance mass flow, resulting in a smaller tip clearance vortex and less losses in the passage. In an effort to reduce the blade tip clearance leakage in turbine designs, Wadia et al. (11) numerically investigated the effects of active jet-flow injected into the tip clearance gap for five differently located injection holes and three jet-flow mass rates. They succeeded to increase the efficiency by $0.35 \%$ with loose tip clearance, and by $0.3 \%$ with tight tip clearance. Hamik and Willinger (12) analytically and numerically investigated the concept patented by Auxier (13) in 1995. The idea is to connect the blade leading edge to the blade tip by an internal channel. Due to the pressure difference, a jet is injected to the tip gap and blocks the leakage flow. With an injection mass flow rate of $0.5 \%$ of the mass flow, they predicted a performance improvement which is independent of the tip gap width. Hu et al. (14) applied the concept proposed by Auxier to an axial

Prepared using sagej.cls 
fan and experimentally investigated the interaction between the tip leakage flow and the tip injection flow by a 2D-PIV. As expected, the authors observed a reduction of the leakage flow. However, the tip injection generated a flow phenomenon similar to Karman vortex street in the wake which exacerbate the complexity and non-stationarity of the flow.

In this study, an active control by air injection into the clearance gap between the shroud and the casing of an axial fan is experimentally investigated. The air is injected in the gap between the rotating shroud and the fixed casing in purpose to control and reduce the leakage flow. This study is experimentally feasible due to a new fan building process. In fact, the fan is built by a rotomolding process and has the property to be hollowed. The air is injected into the fan and exited at the fan periphery in order to counter the leakage flow. The results of this control by air injection are presented in this paper.

\section{Experimental setup}

\section{The axial-flow fan with hollow blades}

The fan (Figure 1) used in this study is a controlled vortex designed axial-flow fan with thick and hollow blades (15). It has six blades with a hub-to-tip radius ratio $\left(R_{\text {int }} / R_{\max }\right)$ equal to 0.337 and a the tip radius $\left(R_{\max }\right)$ equal to $179 \mathrm{~mm}$. This fan is built in polyethylene by a rotomolding process. It is a shaping process which involves a hollow mold. In this case, the mold is loaded with $500 \mathrm{~g}$ of polyethylene powder. Then, the mold is heated at $250^{\circ} \mathrm{C}$ and rotated causing the softened material to disperse and stick to the walls. A 31-mm axial length and 9-mm thick shroud ring was added into the fan design. It is hollow and circular. The incorporation of this shroud ring at the blade tips modified the loss mechanisms $(11 ; 16 ; 17)$. In the present study the effect of the shroud is not investigated. The shroud is used to ensure stronger mechanical properties. The hollow characteristic of the fan allows a fluid circulation inside.

With internal flows into the fan different applications can be developed. In a future work, it is intended investigate the impact of air injection at the trailing edges (Figure 2a). According to Eberlinc et al. (3), injecting air at this position increases locally the velocity flow and tends to reduce the boundary layer stalls. It is also planned to experiment injection at the side of the shroud as shown on figure $2 b$ in order to reduce the leakage flow. In this study, air is injected into the fan and exits at the periphery of the shroud (Figure 2c) in a 4-mm tip clearance gap. Two configurations are explored: the shroud is composed of 16 or 32 injection holes of $4 \mathrm{~mm}$ regularly spaced on the 

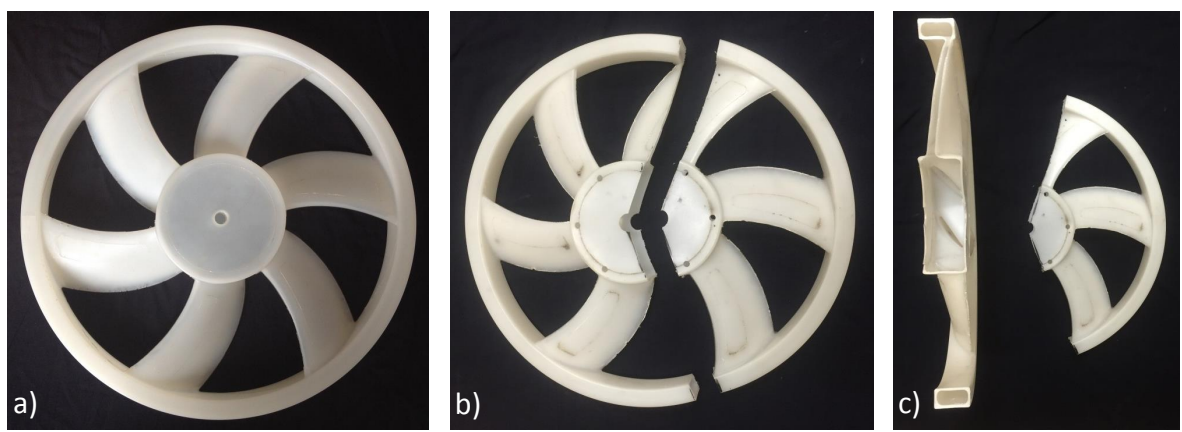

Figure 1. The hollow fan: the whole fan (a) and the fan cut in two parts (b, c).

circumference. The holes are oriented in the direction $(r, \theta, z)=(1,-1,1)$ in such a way to counter the leakage flow. The direction has a component in $\theta$ to compensate the fan rotation.

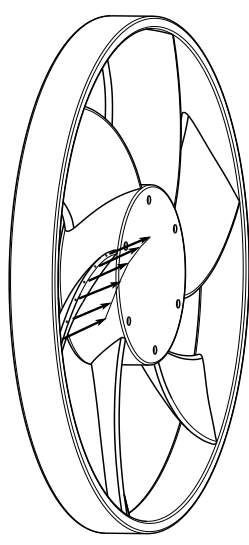

a)

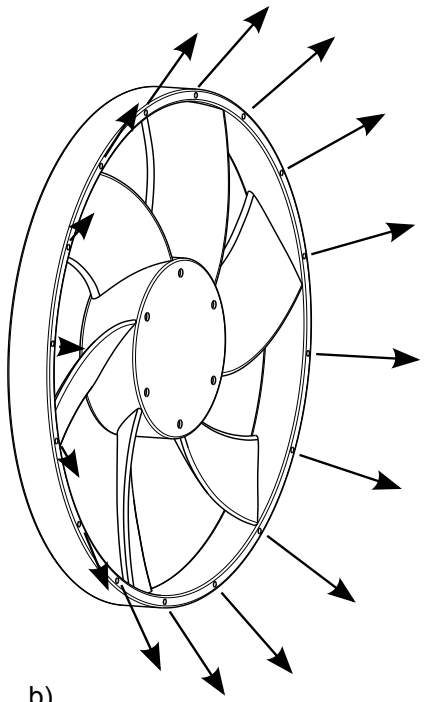

b)

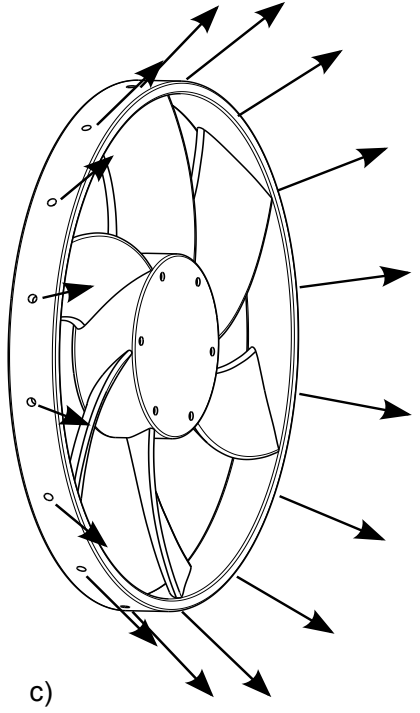

c)

Figure 2. Actual and further investigations: injection at the trailling edge of the blade (a), injection at the side of the shroud (b) and injection at the periphery of the shroud (c).

The carter used in this study has the same thickness as the fan: $46 \mathrm{~mm}$. Thus, many positions between the fan and the carter are possible. The figure 3 (a) represents 3 relative positions: the output position with an offset of $-30 \mathrm{~mm}$ between the fan and the carter, the standard position with no offset and the retracted position with an offset of $+30 \mathrm{~mm}$. This relative position has a strong influence on the fan characteristics 
especially when the injection control is operating. In a similar way, the position of the injection holes on the casing has also a strong influence on the control. The figure 3 (b) represents 3 different positions of the holes on the casing: $x_{\text {holes }}=1 / 4 L, x_{\text {holes }}=1 / 2 L$ and $x_{\text {holes }}=3 / 4 L$. The impacts of those positions are not investigated in this article. The results presented here are obtained for a standard position between the fan and the carter $\left(x_{\mathrm{fan}}=0\right)$ and for the injection holes located at the middle of the casing $\left(x_{\text {holes }}=1 / 2 L\right)$.
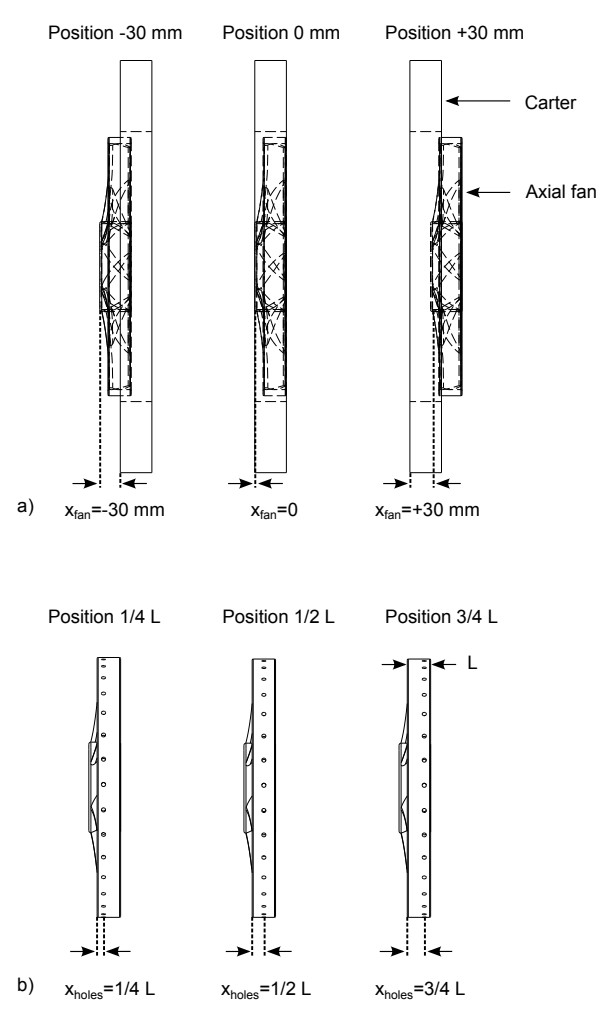

Figure 3. The relative position between the fan and the carter (a) and the position of the injection holes on the casing (b).

\section{The drive system}

To supply air to the fan and the casing, the 3-bar compressed air system of the laboratory is used. A flowmeter and a valve are installed upstream the fan and the casing in order to control the injection. For fan security reasons, the injection is made at the maximum injection flow rate equal to $700 \mathrm{~L} / \mathrm{min}$ at an unknown low pressure. Yet, it is planned to strengthen the fan by using another material rather than polyethylene. A 
specific drive system shown on Figure 4 was built to connect the compressed air system to the hollow fan. The drive system has two functions. It transmits the rotation from the motor to the fan and allows the injection from the compressed air system into the fan. To fulfill its functions, the drive system is composed of two shafts connected through a pulley and belt system. The first shaft connects a 4-kW motor to the pulley and belt system. On this shaft a HBM strain gauge transducer is installed. It measures the torque with an uncertainty corresponding to $0.1 \%$ of the full scale. In this case the full scale is equal to 5 N.m. The second shaft connects the pulley and belt system to the fan. It also connects the compressed air system to the fan. This connection is possible because the shaft has the particularity to be hollow. Into the shaft, a rotary joint is used to inject air from a stationary source to a rotating piece. The rotary joint is brand Deublin and has the reference 1115-000-200. The fan angular velocity is measured with a tachymeter of relative precision $\pm 0.2 \%$.

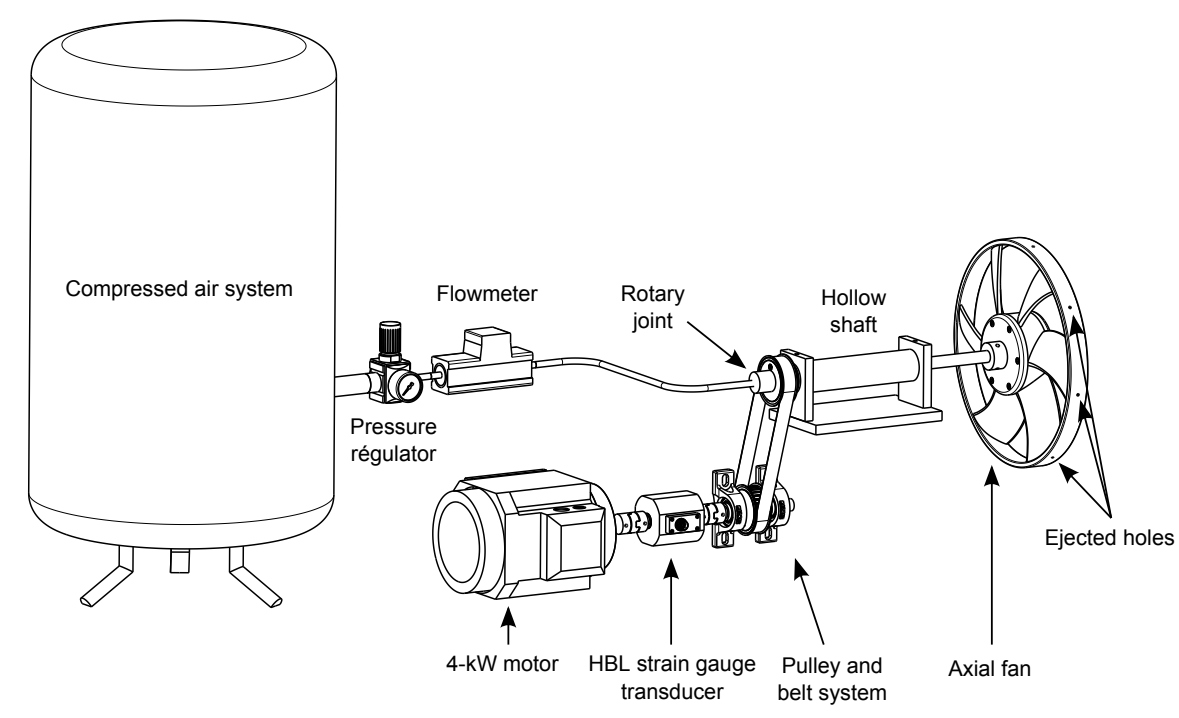

Figure 4. The fan drive system.

\section{The test bench}

To determine the global performances of the fan, an air suction test bench was used. This experimental facility showed on Figure 5 was designed and built at the laboratory according to the ISO 5801 standard [10]. It consists of a cuboid of size $1.3 \mathrm{x} 1.3 \mathrm{x}$ $1.8 \mathrm{~m}$. A pierced plate inside it prevents flow prerotation. The air flow rate is set and measured according to the ISO-5167 norm [11] by setting the aeraulic resistance of the

Prepared using sagej.cls 
bench through diaphragms of various sizes. The elevation pressures are measured with an absolute precision of $\pm 0.1 \mathrm{~Pa}$.

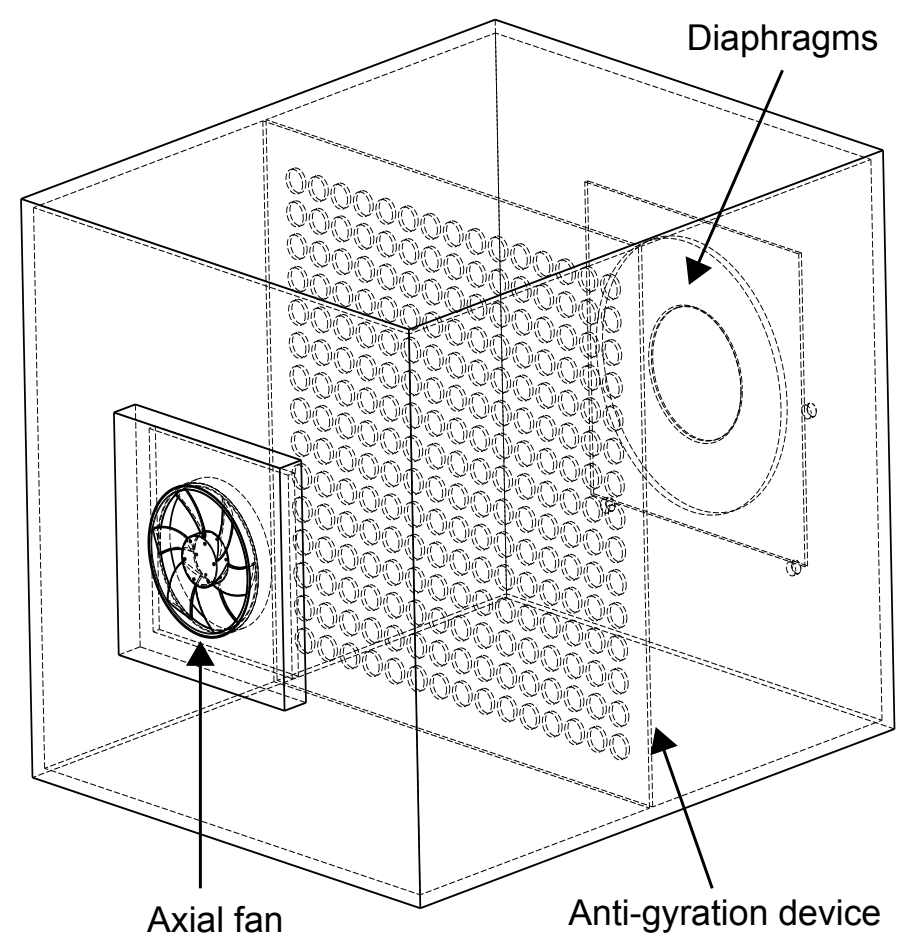

Figure 5. ISO-5801 test bench. The dimensions are $1.3 \times 1.3 \times 1.8 \mathrm{~m}$. The fans suck the flow through the test bench.

\section{Results}

The experiment was carried out for 3 rotational speeds, 5 injection rates and 2 configurations with a different number of injection holes at the fan periphery. The results are presented on Figure 6. The figure represents the fan characteristics for a rotational speed equal to $1000 \mathrm{rpm}(\mathrm{a}, \mathrm{d}), 1500 \mathrm{rpm}(\mathrm{b}, \mathrm{e})$ and $2000 \mathrm{rpm}(\mathrm{c}, \mathrm{f})$, and for a number of injection holes equal to $16(\mathrm{a}, \mathrm{b}, \mathrm{c})$ and $32(\mathrm{~d}, \mathrm{e}, \mathrm{f}) . \psi$ and $\phi$ are respectively the static pressure and the flow coefficient:

Prepared using sagej.cls 


$$
\begin{aligned}
\psi & =\frac{2 \Delta p}{\rho u^{2}} \\
\phi & =\frac{4 q_{v}}{\pi D^{2} u}
\end{aligned}
$$

In order to quantify the impact of the control by air injection, the fan characteristics are plotted for 5 different injection rates. These are normalized and reported to the maximum fan flow rate. The maximum fan flow rate depends on the rotation speed and it is equal to the rate when the static pressure difference is zero for the configuration with no injection. The maximum fan flow rate is respectively equal to $0.39 \mathrm{~m}^{3} / \mathrm{s}, 0.67$ $\mathrm{m}^{3} / \mathrm{s}$ and $0.97 \mathrm{~m}^{3} / \mathrm{s}$ for corresponding rotation speeds equal to $1000 \mathrm{rpm}, 1500 \mathrm{rpm}$ and $2000 \mathrm{rmp}$. The black curves represent the fan characteristics with no injection. These are identical for $1500 \mathrm{rpm}$ and $2000 \mathrm{rpm}$ and different for $1000 \mathrm{rpm}$. This difference probably comes from additional losses appearring at low Reynolds number (18). The Reynolds numbers are respectively about $1.2010^{5}, 1.8010^{5}$ and $2.4010^{5}$ for a rotation speed equal to 1000,1500 and $2000 \mathrm{rmp}$ at the design flow rate, $\phi=0.17$. The Reynolds numbers are defined as follow :

$$
R_{e}=\frac{\rho W R_{\max }}{\mu}
$$

At low flow rate, the injection does not modify the fan characteristics regardless of the rotational speed and the number of holes. When increasing the flow rate, however, the pressure coefficient increases as well. This is well observable when flow rates become sufficiently high (7). As expected, the pressure coefficient increases with the injection rate. Nevertheless, a saturation phenomenon can be observed. For example, on Figure 6 (a), an injection rate equal to $6 \%$ does not seem to affect the pressure coefficient comparatively to an injection rate equal to $5.1 \%$. It can be conjectured that this phenomenon appears when the leakage flow is drastically reduced; so that an additional injection rate is useless. At high rotation speed, the control by injection seems to be less significant. However, this result is to be linked with the value of the normalized injection rate which decreases with the rotation speed. At $1000 \mathrm{rpm}$, the injection rate is equal to $6 \%$ of the maximum fan flow rate while at $2000 \mathrm{rpm}$ the ratio is only $4.6 \%$.

To analyze the influence of the number of holes, the figure 7 is plotted. On this figure, the power gain added by the control versus the normalized injection rate are presented

Prepared using sagej.cls 

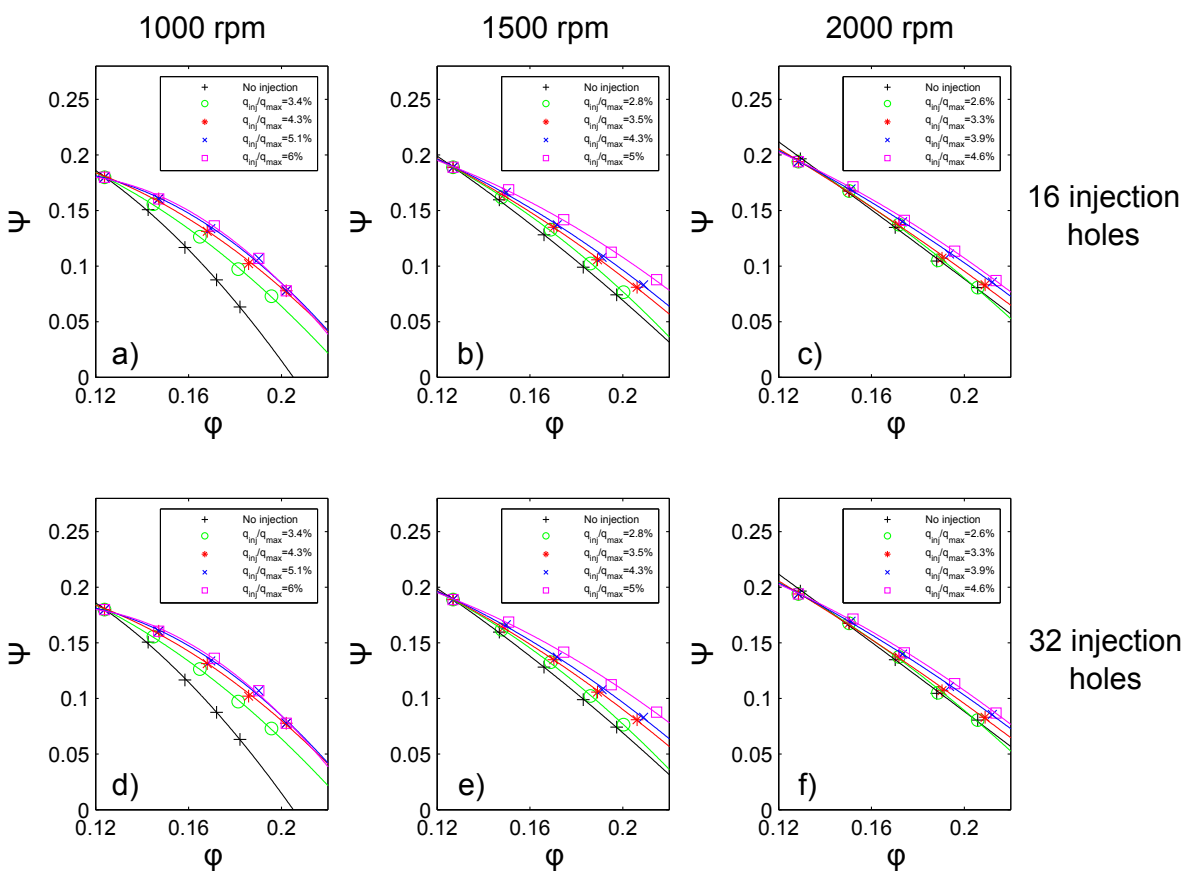

Figure 6. Comparison of aerodynamic characteristic of the axial fan for 5 different injection rates and for 3 rotation speeds: 1000 (a, d) 1500 (b, e) and 2000 (c, f) rpm and for 16 (a, b, c) and 32 holes $(d, e, f)$ at the fan periphery.

for rotation speeds, $1000 \mathrm{rpm}(\mathrm{a}, \mathrm{d}, \mathrm{g}, \mathrm{j}, \mathrm{m}), 1500 \mathrm{rpm}(\mathrm{b}, \mathrm{e}, \mathrm{h}, \mathrm{k}, \mathrm{n})$ and $2000 \mathrm{rpm}(\mathrm{c}$, $\mathrm{f}, \mathrm{i}, 1, \mathrm{o})$ and for the 5 throttles. This gain is defined as follow:

$$
\text { Gain }=\frac{P-P_{0}}{P_{0}}
$$

$P=q_{v} \Delta P$ is the power delivered by the fan and $P_{0}$ is the power delivered by the fan for $q_{\text {inj }}=0$. Each throttle corresponds to a different diaphragm of the test bench (Figure 5) and so it corresponds to a different aeraulic resistance of the circuit. The resistance increases with the number of throttle. For each figure, the results obtained for the 2 configurations are represented. The results for 16 and 32 injection holes are respectively plotted with circle and cross markers. In this study, the active control by air injection adds an increase up to nearly $40 \%$ in the delivered power. For an identical normalized injection rate $\left(q_{\mathrm{inj}} / q_{\max }\right)$ the most important gains were obtained for the lowest rotation speed $(1000 \mathrm{rpm})$ and the lowest aeraulic resistance (throttle 1). As expected, the delivered power does not change between the 2 configurations when there is no injection. However, for the same injection rate, the delivered power is higher for 
the configuration with 16 holes than for the configuration with 32 holes. This result may be understood by referring to the velocity injection at the periphery of the fan. By mass conservation, for the same injection rate, the configuration with 16 holes has a velocity injection twice higher than the configuration with 32 holes. Thus in this case, a higher velocity injection spreads across 16 holes seems to better reduce the leakage flow than a lower velocity injection spreads across 32 holes. Regardless the number of holes, an increase of the injection rate increases the power gain. However, the saturation phenomenon could also be observed in this Figure especially at high power gain $(\mathrm{a}, \mathrm{d})$ and at low working flow rate $(\mathrm{k}, \mathrm{l}, \mathrm{m}, \mathrm{n}, \mathrm{o})$. When this phenomenon appears an increase of the injection rate and the modification of the number of holes have no influence on the control. The authors think that this phenomenon appears when the leakage flow becomes nonsignificant.

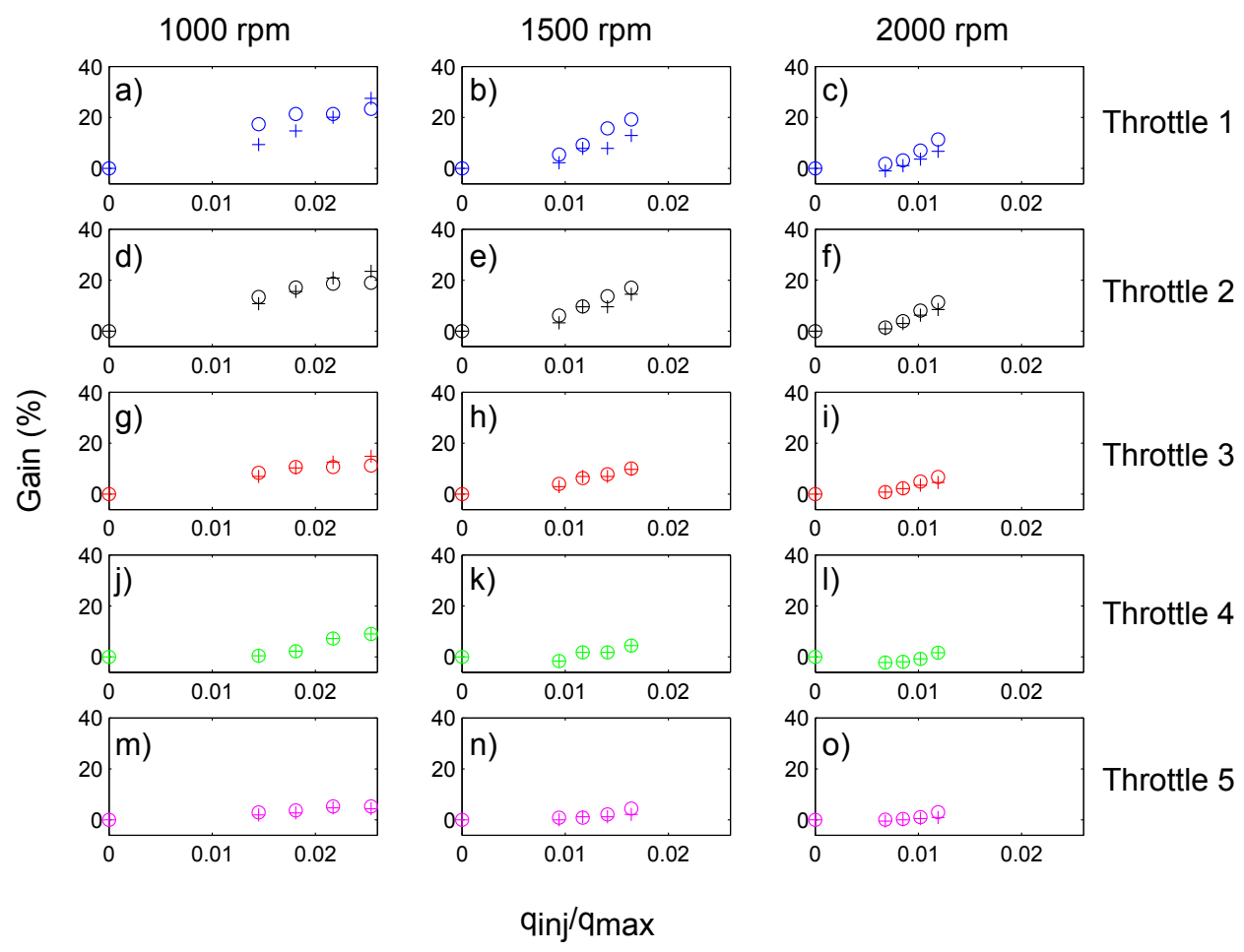

Figure 7. The power gain added by the control for 3 rotation speeds: 1000 (a, d, g, j, m), 1500 (b, e, h, k, n) and $2000 \mathrm{rpm}$ (c, f, i, l, o) and 5 throttles. +: results for 16 injection holes. o: results for 32 injection holes. 


\section{Conclusion}

A rotomolding process was used to build a hollow fan in order to study the leakage flow control by air injection at the fan periphery. To drive the fan and simultaneously control the air injection, a specific drive system was designed and built. Experiments were carried out and conducted for 5 injection rates, 3 rotation speeds and 2 configurations, 16 and 32 holes at the fan periphery. This control leads to an improvement of the fan characteristics. An increase up to nearly $40 \%$ in the delivered power was registered. In fact, by reducing the leakage flow, the blades could work better especially at the periphery. The experimental results show the control is particularly efficient at high flow rate. An increase of the injection rate generates higher pressure coefficients. In this case, for the same injection rate, better results are obtained for the configuration with 16 holes at the fan periphery than the configuration with 32 holes. A saturation phenomenon is also observed and is likely due to weak leakage flow. As perspectives, the authors plan to consider the impact of air injection at the trailing edges. Injecting air at the trailing edges increases locally the velocity flow and tends to reduce the boundary

layer stalls. Instead of flow injection, it would be also interesting to experiment suction flows for fan control.

\section{References}

[1] Weigl HJ, Paduano JD, Frechette LG, Epstein AH, Greitzer EM, Bright MM, et al. Active stabilization of rotating stall and surge in a transonic single stage axial compressor. In: ASME 1997 International Gas Turbine and Aeroengine Congress and Exhibition; 1997. .

[2] Rhee SH, Kim SE, Ahn H, Oh J, Kim H. Analysis of a jet-controlled high-lift hydrofoil with a flap. Ocean Eng 2003;30(16):2117-2136.

[3] Eberlinc M, Širok B, Hočevar M. Experimental investigation of the interaction of two flows on the axial fan hollow blades by flow visualization and hot-wire anemometry. Exp Therm Fluid Sci 2009;33(5):929-937.

[4] Eberlinc M, Širok B, Dular M, Hočevar M. Modification of axial fan flow by trailing edge self-induced blowing. J Fluids Eng 2009;131(11):111104.

[5] Eberlinc M, Širok B, Hočevar M, Dular M. Numerical and experimental investigation of axial fan with trailing edge self-induced blowing. Forsch Ingenieurwes 2009;73(3):129_ 138.

[6] Wang Y, Zhao L. Investigation on the effect of trailing edge ejection on a turbine cascade. Appl Math Modell 2013;37(9):6254-6265.

Prepared using sagej.cls 
[7] Neuhaus L, Neise W. Active control to improve the aerodynamic performance and reduce the tip clearance noise of axial turbomachines with steady air injection into the tip clearance gap. In: Notes on Numerical Fluid Mechanics and Multidisciplinary Design; 2007. .

[8] Morris SC, Foss JF. An aerodynamic shroud for automotive cooling fans. J Fluids Eng 2001;123(2):287-292.

[9] Neal DR, Foss JF. The application of an aerodynamic shroud for axial ventilation fans. $J$ Fluids Eng 2007;129(6):764-772.

[10] Niu M, Zang S. Experimental and numerical investigations of tip injection on tip clearance flow in an axial turbine cascade. Exp Therm Fluid Sci 2011;35(6):1214-1222.

[11] Wadia AR, Szucs PN. Inner workings of shrouded and unshrouded transonic fan blades. $J$ Turbomach 2008;130(3):031010.

[12] Hamik M, Willinger R. An innovative passive tip-leakage control method for axial turbines: Basic concept and performance potential. J Therm Sci 2007;16(3):215-222.

[13] Auxier TA. Aerodynamic tip sealing for rotor blades; 1995, No. 5.403.158.

[14] Hu J, Kong X, Li Z, Zhang Y, Xu J. Experimental investigation of aerodynamic interaction between tip leakage flow and spontaneous tip injection flow using 2D-PIV. Exp Therm Fluid Sci 2014;54:127-135.

[15] Sarraf C, Nouri H, Ravelet F, Bakir F. Experimental study of blade thickness effects on the overall and local performances of a controlled vortex designed axial-flow fan. Exp Therm Fluid Sci 2011;35(4):684-693.

[16] Engin T, Gur M, Scholz R. Effects of tip clearance and impeller geometry on the performance of semi-open ceramic centrifugal fan impellers at elevated temperatures. Exp Therm Fluid Sci 2006;30(6):565-577.

[17] Yoon S, Curtis E, Denton J, Longley J. The effect of clearance on shrouded and unshrouded turbines at two levels of reaction. J Turbomach 2014;136(2):021013.

[18] Bakir F. Méthode de dimensionnement et d'analyse des machines de compression hélicocentrifuges en régime incompressible. Ph.D. thesis. Arts et Métiers, France; 1992.

Prepared using sagej.cls 